University for Business and Technology in Kosovo

UBT Knowledge Center

UBT International Conference

2018 UBT International Conference

Oct 27th, 1:30 PM - 3:00 PM

\title{
Evolution of a Course: Instructional Design Elements and Impacts
}

\author{
Michele Gibney \\ University of the Pacific, mgibney@pacific.edu \\ Anita Mirijamdotter \\ Linnaeus University, anita.mirijamdotter@Inu.se \\ Mary M. Somerville \\ University of the Pacific, msomerville@pacific.edu \\ Patrik Elm \\ Linnaeus University, patrick.elm@Inu.se \\ Krenare Pireva Nuci \\ University for Business and Technology, krenare.pireva@ubt-uni.net
}

Follow this and additional works at: https://knowledgecenter.ubt-uni.net/conference

Part of the Education Commons

\section{Recommended Citation}

Gibney, Michele; Mirijamdotter, Anita; Somerville, Mary M.; Elm, Patrik; and Nuci, Krenare Pireva, "Evolution of a Course: Instructional Design Elements and Impacts" (2018). UBT International Conference. 125. https://knowledgecenter.ubt-uni.net/conference/2018/all-events/125

This Event is brought to you for free and open access by the Publication and Journals at UBT Knowledge Center. It has been accepted for inclusion in UBT International Conference by an authorized administrator of UBT Knowledge Center. For more information, please contact knowledge.center@ubt-uni.net. 


\title{
Evolution of a Course: Instructional Design Elements and Impacts
}

\author{
Michele Gibney $^{1}$, Anita Mirijamdotter ${ }^{2}$, Mary Somerville ${ }^{3}$, Patrik Elm ${ }^{4}$, \\ Krenare Pireva ${ }^{5}$ \\ ${ }^{1}$ University of the Pacific, 3601 Pacific Ave., Stockton, CA 95211, USA \\ mgibney@pacific.edu \\ ${ }^{2}$ Linnaeus University, P G Vejdes väg, 35195 Växjö, Sweden \\ anita.mirijamdotter@1nu.edu \\ ${ }^{3}$ University of the Pacific, 3601 Pacific Ave., Stockton, CA 95211, USA \\ msomerville@pacific.edu \\ ${ }^{4}$ Linnaeus University, P G Vejdes väg, 35195 Växjö, Sweden \\ patrik.elm@lnu.edu \\ ${ }^{5}$ University of Business and Technology, Lagjja Kalabria,10000 Prishtine, Kosovo \\ krenare.pireva@ubt-uni.net
}

\begin{abstract}
During the 2017 Spring semester, international educators from Sweden and the United States collaborated on delivery of an Information Systems, Analysis, Design and Modeling graduate course at the University for Business and Technology (UBT) in Kosovo. In the Spring of 2018, the team taught course was offered a second time, with both graduate and undergraduate students. In the first year, student work focused on the conceptual design of a UBT Knowledge Center ecosystem, using Soft Systems Methodology (SSM) co-design tools. The Spring 2018 course built upon and expanded this work through more granular exploration of possible local systems designs for making local knowledge discoverable, employing SSM and emphasizing Informed Learning to foster an enriched exploration of the topic. Differences between the pedagogical course design and student experience reflections will be explored in this paper to highlight the impact of 'flipped classroom' teaching and crossdisciplinary/cross-degree group work, within the larger context of systems thinking educational efficacy.

Keywords: Soft Systems Methodology (SSM), Near-peer mentoring, Coteaching, Flipped Classroom, Interdisciplinary collaboration, Informed learning
\end{abstract}

\section{Introduction}

The University for Business and Technology (UBT) was established in 2001 by founder and now Rector Edmond Hajrizi in Pristina, Kosovo. In recent years, one of the primary goals of the University has been to develop, staff, and curate a 
Knowledge Center comprised of physical and digital books and a digital repository of knowledge produced by UBT faculty, students and staff. The goal of this latter initiative is to "build a national knowledge base in the (primarily) Albanian language, through intentionally building upon earlier student and faculty research, scholarship and creative work" [1]. Collecting, preserving and disseminating a substantial body of work in both the Albanian and English languages "ensures relevance to Kosovar community readers and fortifies UBT's lead role in national and regional knowledge generation," [2]. Shared commitment to achieve the vision of a UBT Knowledge Center has led to a collaborative multi-year teaching partnership between UBT, Linnaeus University in Sweden, and University of the Pacific in the United States.

\subsection{An International Partnership}

In March 2017, faculty from Linnaeus and Pacific traveled to Pristina to co-teach a 6 credit, graduate level course on Information Systems, Analysis, Design and Modeling at UBT. The modular course was designed through a four month planning process, in collaboration with staff at UBT. A 'flipped classroom', was utilized whereby students were given an assignment three weeks before the course start, to complete in advance. This preparatory work included reading seminal texts about Soft Systems Methodology (SSM), founded by Peter Checkland in England. Other readings on Informed Systems, which emphasizes the aspect of using information to learn during systems design, further framed class discussion and design activities [3].

Subsequently in the May 2018 course, a 'flipped classroom' approach and SSM were used again; however, there were a few key differences in instructional design. In the 2017 version, only graduate students from Information Systems (IS) were enrolled; in the 2018 version, a mixed group of students came from the Computer Science (CS) undergraduate and IS graduate programs. Additional international staff from Pacific and Linnaeus, as well as one UBT faculty member, were added as members of the co-teaching team. Lastly, more emphasis in 2018 was placed on the theories of 'informed learning' advanced by Christine Bruce in Australia. This content served to build upon prior experiences of 'using information to learn' [4], within a larger context of the co-created digital repository of UBT generated knowledge.

\section{Grounding Theory in Practice}

In order to fully understand the pedagogical underpinnings across the two iterations of the course, it is important to cover the theories of SSM, co-teaching, flipped classroom, informed learning, near-peer mentoring, and interdisciplinary collaboration in relation to the in-practice application of them to the classes. Highlights are presented below in a literature review. 


\subsection{Soft Systems Methodology (SSM) (2017 \& 2018)}

Soft Systems Methodology (SSM) was developed by Peter Checkland in 1981 [5]. One of the primary benefits of SSM in the pedagogical context of the course was that it "acknowledges the social context of learning - that knowledge is acquired and understood through action, interaction, and sharing with others" [3]. This was expressed during class in the multiple co-design activities that students participated in, drawing rich pictures and engaging in small discussion groups prior to sharing with the larger group. When approaching a real world problem such as the absence of a digital repository, this methodology is eminently useful. It can also be described as Participatory Action Research (PAR) wherein real-life stakeholders in the problem situation are defining the problem; in that case, the research is "socially relevant...in the production of practical knowledge that drives real changes" [6]. Relatedly, Checkland identified an extended version of SSM which requires the investigation and definition of the problem situation to be done "through a cultural dimension, which includes the analysis of the intervention, as well as of the social and political systems," [7]. By utilizing background methods of SSM and PAR in both courses, students were actively engaged in a case study with actual context to their lives and education, which has been shown to create an effective learning environment [8].

Student reflection papers from 2017 included statements such as "[a]nd I can say that my life will have two eras, before SSM and after SSM," and in learning about SSM, they realized "we need to consider many other factors and variables so that we do not repeat the same mistakes but rather think in long run and with social, environment, etc. wide approach." In 2018, there was almost unanimous approval in the 22 student reflection papers for teaching SSM. Even one who was unsure about SSM in the beginning stated at the end, "it took only four days of lectures to change my mind about the SSM which made me into a different person."

\subsection{Co-teaching $(2017 \& 2018)$}

Co-teaching can have many benefits in the classroom, pedagogically and professionally. Seeing professionals co-teach can further student engagement and collaboration - through modeling - in class as well as in the workplace. That said, through thoughtful and thorough planning, the 'down side' of co-teaching must be avoided - i.e., the possibility of repetitive material, contradictory assertions, and personality conflicts, which can lead to student stress and cognitive insecurity [9].

One student's reflection paper from 2017 included thoughts on the co-teaching aspect as "I enjoyed the effort that they put in finding the most appropriate way for us to understand and the kindness that they show during the course ... it made me be more active, focused and open minded. I'm certain the whole group felt joy which is rare in lectures." Co-teaching was mentioned positively in seven of the 22 student reflection papers from 2018. Positive remarks on the co-teaching experience included "great focus and cooperation because it also affects our engagement," "gave us a new spirit different from what we have been taught earlier," "time has passed very fast because we have had a great time and we got new knowledge and new society and we have exchanged new ideas," "good organization and coordination from professors 
helped us understanding," and "it is important to note that the professors created a learning environment where all student skills were represented and all students were able to succeed."

\subsection{Flipped Classroom (2017 \& 2018)}

Jonathan Bergman and Aaron Sams are generally credited as the originators of the phrase 'flipped classroom' [10], when they began flipping their Chemistry classes in 2007. The purpose of a 'flipped classroom' is to "introduce students to course content outside of the classroom so that students can engage that content at a deeper level inside the classroom" [11]. A number of studies have shown the benefits of flipped classroom pedagogy: students perform better on exams, are more actively engaged, take ownership of their learning, and display better developed team-based skills. Conversely, a seemingly equal number of studies provides a list of challenges: demand on instructor time, lack of institutional funding and on-going support, and student resistance to change [10]. Other research has shown that the benefits of a flipped classroom may be better expressed in student satisfaction rather than academic gains - "engagement with academic content, educators and peers leading to the strengthening of lifelong learning" [12].

Several of the 10 reflection papers from 2017 appreciated the flipped classroom style with comments such as "[i]t made me be more active member in the class rather than a spectator and listener" and "instead of wasting a lot of time in lecturing about the topic in class, I did the reading ... and then in class, with perfectly matching backgrounds, with three Lecturers we did more hands-on and engaged more." In addition, many of the 22 reflection papers addressed the flipped classroom approach positively referring to it as "good", "something different and awesome", "a great opportunity to understand more ... prior to direct meeting in classroom", and "effective". One student even identified some of the benefits addressed in the context highlights above by writing, "Flipped learning certainly addresses some issues that professors and students face - time, resources, learning styles, etc. The concept of flipped learning can lead to us as students to learn easier, more efficient, engaging, and meaningful."

\subsection{Informed Learning (2018)}

Informed learning is the acknowledgement that learning happens in many broadly defined ways. First espoused by Christine Bruce in 2008, she has since explained it as being aware of how information is used when learning, in the classroom and beyond [13]. Informed learning is experienced as a framework of seven aspects: (1) Information and communication technologies; (2) Information sources; (3) Information and knowledge generation processes; (4) Information curation and knowledge management; (5) Knowledge construction and worldview transformation; (6) Knowledge sharing and knowledge extension; and (7) Professional wisdom and continuous learning [14]. 
In year two, outcomes focus had evolved from the initial course where a major problem was student-defined as "you are part of an institution and you are willing to generate some knowledge, but have no way of storing it or sharing it; or you're looking for some important information that would have helped on your work but you have no way of reaching it" [15]. During the 2018 course, one of the first co-designed activities by the students was to draw Rich Pictures identifying their research process when first assigned a project: "[r]esults demonstrated that while students typically used academic library resources, building upon the work of published others, they never used content produced by their UBT peers or professors" [1], due to a lack of institutional repository environment which would allow storage of their work in order to reuse it in the future. Through analysis of student processes, instructors and students recognized that students currently only utilized numbers 1-3 of the seven informed learning aspects listed above - technology, sources, and processes. Instructors "recognized that [students] lacked explicit ways to advance categories 4-7, which 'bridge' from individual to collective use through curating, organizing, accessing, and using information for creating more knowledge". [1]

Using the theories of informed learning in a teaching environment, as was done in 2018 at UBT, stressed the importance to the students of paying attention to how they were learning, especially being aware of the process. As one student noted in the reflection paper, "I learned how to learn." Taking this further in their educational aims, students recognized that they could transpose the theory on other classes and situations. Two student reflection papers corroborated this by stating, "this will not only help me in my career but also in personal and academic life," and "learning is a process that never stops ... learning is something as a universe, infinite and vast..."

\subsection{Near-peer Mentoring (2018)}

Another new element in the second year course was 'near-peer mentor' which, in this context, is defined as a graduate student to an undergraduate student. In the initial version of the course, the class was composed solely of graduate students; however, in the 2018 version, both graduate and undergraduate students were included. Mentorship in the STEM fields has a well-established history of success in using 'near-peer mentoring' as an educational model, including advancing the mentees as early career specialists [16]. Some studies on the reciprocal relationship benefits for mentors have identified the rewards of helping others and obtaining and applying career-related knowledge [17].

Unfortunately, most of the student reflection papers did not explicitly address the effects of near-peer mentoring in the classroom, either positively or negatively. While many students mentioned the positive effect of teamwork and interdisplinary learning, near-peer mentoring was only mentioned once. As one student wrote, "[b]eing a bachelor student in Computer Science and having to work with master students in Information Systems was a very enriching experience.” However, class conversations did include undergraduates' gratitude for graduate near-peers' attention during activities and presentations. Further attention to this aspect may be desirable in the next course iteration. 


\subsection{Interdisciplinary collaboration (2018)}

Interdisciplinary research is defined by the National Academies of Science as "a mode of research by teams or individuals that integrates information, data, techniques, tools, perspectives, concepts, and/or theories from two or more disciplines or bodies of specialized knowledge to advance fundamental understanding or to solve problems whose solutions are beyond the scope of a single discipline or area of research practice" [18]. Research undertaken in an interdisciplinary, or interprofessional, fashion can lead to the development of "more advanced epistemological beliefs, enhanced critical thinking ability and metacognitive skills, and an understanding of the relations among perspectives derived from different disciplines" [19].

Of particular note in 2018 is the fact that students from both CS and IS were enrolled in the course. Combining students from these departments allowed for an expansion of ideas and skill learning on both sides, which translated into solution finding and problem solving. The students were divided into five groups. Three groups were an equal mix of students, one group was all IS and one group was all CS students. The CS students, influenced by their technical skills, analyzed and designed their Knowledge Center proposal more from a technical aspect whereas the IS students tended to emphasize the importance of the Knowledge Center from a data perspective. Based on instructor observation, groups with a mix of students from both sides were able to have equal representation from both perspectives and consequently developed richer findings within the course assignments.

As interdisciplinary faculty interactions demonstrated, interprofessional collaboration is a valuable skill, particularly in the current professional and social contexts where problems can be more complex and require more than one way of looking at them [20]. The students assigned into groups containing representatives from both discipline, who were asked to collaboratively identify, define, and provide solutions to a situated problem, enjoyed practical experience in real world interprofessional collaboration.

Twenty of the 22 student reflection papers addressed the aspect of teamwork within the 2018 course. The most common positive word used to describe the collaborative process was "energetic". One noted that it was a "unique opportunity...to see how other people think and write ... processes and the strategies", that it allowed them to "apply some level of negotiation" between disciplines in the final shape of the product, and, finally, it "facilitated my ability to skillfully work in group settings in the future." One of the papers from a graduate student in IS addressed the interdisciplinary nature of the group even more explicitly, stating, "computer sciences had a bit different approach on dealing with the assignment we had, but when we discussed about SSM importance and functions we succeeded on completing the task."

Interestingly, the teaching group was also interdisciplinary having individuals from CS, IS and Library Science. This interprofessional collaboration may have had a direct impact on class learning outcomes; it definitely was expressed in the instructional design of the course as multiple viewpoints and consideration were thoughtfully considered. 


\section{Conclusion}

In year one (2017), evaluation of the student reflection papers and final assignments "revealed high level of knowledge acquisition and advanced understanding. Also, there were no dropouts for the course ... suggestive of their high level of engagement" [3]. SSM, co-teaching, and the flipped classroom were all beneficially experienced by students in the first year and reflected in their papers at the end of the course. In 2018, student response to the pedagogical model continued to be favorable to the 2017 elements of SSM, co-teaching and flipped classroom and, in addition, their response was also positive to informed learning theories and interdisciplinary collaboration. While near-peer mentoring was a factor in year two, it was not addressed extensively in the student reflection papers at the close of the course and could be an area for additional study in following iterations. As with year one, there were no dropouts in year two, which offers further evidence that the pedagogical model, grounded in a local problematical situation, is successful in engaging and maintaining student interest and, hence, learning impact.

\section{References}

1. Somerville, M. M., Mirijamdotter, A., Bruce, C., Stoodley, I. D., \& Pireva, K.: From Global Theories to Local Practice and Original Knowledge: Learning the Way through Systems CoDesign. IFLA World Library and Information Congress 2018, Kuala Lumpur, Malaysia (2018) 2. Hajrizi, E., Somerville, M., Mirijamdotter, A.: The UBT Knowledge Center: A collaborative design approach. Paper presented at University for Business and Technology $6^{\text {th }}$ International Conference on Education and Development in Durres, Albania. (2017)

3. Mirijamdotter, A., Somerville, M. M., Salavati, S., Hajrizi, E.: University for Business and Technology Knowledge Center. Making local knowledge visible. In: Proceedings of the $61^{\text {st }}$ Annual Meeting of the International Society for the Systems Sciences (ISSS). From Science to Systemic Solutions - Systems Thinking for Everyone, Vienna, Austria (2017)

4. Bruce, C. S.: Informed learning. Association of College and Research Libraries, American Library Association, Chicago, IL (2008)

5. Checkland, P.: Systems Thinking, Systems Practice. John Wiley \& Sons, Chicester, United Kingdom (1981)

6. Sanchez, A. \& Mejia, A.: Learning to support learning together: an experience with the soft systems methodology. Educational Action Research, Vol. 16(1) (2008, March) pp. 109-124

7. Checkland, P. \& Scholes J.: Soft Systems Methodology in Action. John Wiley \& Sons, Toronto, Canada (1990)

8. Kolb, D. A.: Experiential learning: experience as the source of learning and development (Vol. 1), Prentice-Hall, Englewood Cliffs, New Jersey (1984)

9. Lock, J., Rainsbury, J., Clancy, T., Rosenau, P., Ferreira, C.: Influence of Co-teaching on Undergraduate Student Learning: A Mixed-Methods Study in Nursing. Teaching \& Leaning Inquiry 6(1) (2018) pp. 38-51

10. Mohan, D.: Flipped Classroom, Flipped Teaching and Flipped Learning in the Foreign/Second Language Post-Secondary Classroom. Nouvelle Revue Synergies Canada 11 (2018) pp. 1-12

11. Strayer, J. F.: How learning in an inverted classroom influences cooperation, innovation and task orientation. Learning Environ Res 15 (2012) pp. 171-193 
12. Smallhorn, M.: The Flipped Classroom: A learning model to increase student engagement not academic achievement. Student Success 8(2) (2015) pp. 43-53

13. Bruce, C. S., Demasson, A., Hughes, H., Lupton, M., Maybee, C., Mirijamdotter, A., Sayyad Abdi, E., \& Somerville, M. M.: Information literacy and informed learning: Conceptual innovations for IL research and practice futures. Journal of Information Literacy, 11(1), (2017) pp. 4-22

14. Bruce, C. S., Hughes, H., \& Somerville, M. M.: Supporting informed learners in the $21^{\text {st }}$ Century. Library Trends 60(3) (2012) pp. 522-545

15. Hajrizi, E., Ramadani, E., Bivolakum, R., Gosalci, D., \& Konushefei, J.: The Creation of the Knowledge Center. University for Business and Technology student research paper, Pristina, Kosovo (2017)

16. Tenenbaum, L. S., Anderson M. K., Jett, M., and Yourick, D. L: An innovative near-peer mentoring model for undergraduate and secondary students: STEM focus. Innovative Higher Education 39(5) (2014) pp. 375-385

17. Eby, L. T., Durley, J. R., Evans, S. C., Ragins, B. R.: The relationship between short-term mentoring benefits and long-term mentor outcomes. Journal of Vocational Behavior 69 (2006) pp 424-444

18. National Academy of Sciences, National Academy of Engineering, and Institute of Medicine.: Facilitating Interdisciplinary Research. Washington, DC: The National Academies Press (2005) https://doi.org/10.17226/11153

19. Ivanitskaya, L., Clark, D., Montgomery, G., and Primeau, R.: Interdisciplinary learning: Process and Outcomes. Innovative Higher Education 27(2) (2002, Winter) pp. 95-111

20. Alexandru, M.: Interprofessional Collaboration Skills Training for Social and Education Fields - A Module Proposal. Revista de Pedagogie/Journal of Pedagogy, 1 (2018), 65-75. 